\title{
Protein hydrolysates stimulate proglucagon gene transcription in intestinal endocrine cells via two elements related to cyclic AMP response element
}

\author{
J.-C. Gevrey ${ }^{1}$ - M. Malapel ${ }^{1}$ J. Philippe ${ }^{2}$ G. Mithieux ${ }^{3}$ - J.-A. Chayvialle ${ }^{1}$ J. Abello $^{1} \cdot$ M. Cordier-Bussat $^{1}$ \\ ${ }^{1}$ INSERM Unité 45, IFR 62, Faculté de Médecine RTH Laënnec, Lyon, France \\ 2 Diabetes Unit, University Hospital Geneva, Switzerland \\ 3 INSERM Unité 449, IFR 62, University Laënnec, Lyon, France
}

\section{Abstract}

Aims/hypothesis. Protein hydrolysates (peptones) increase not only glucagon-like peptide-1 (GLP-1) secretion but also transcription of the proglucagon $(P G)$ gene in the intestine. The critical physiological roles of gut-derived GLPs raised hope for their therapeutic use in several disorders, especially GLP-1 in diabetes. We aimed to investigate the molecular mechanisms involved in this nutrient $-P G$ gene interaction.

Methods. Wild-type and mutated $P G$ promoter fragments fused to the luciferase reporter gene were transfected into enteroendocrine STC-1 cells, which were then either treated or not with peptones. Co-transfection with expression vectors of dominant-negative forms of cAMP response element binding protein (CREB) and protein kinase A (PKA) proteins were performed, as well as electrophoresis mobility shift assays.

Results. Deletion analysis showed that the promoter region spanning between -350 and -292 bp was crucial for the transcriptional stimulation induced by pep- tones. Site-directed mutagenesis of the canonical cAMP response element $\left(\mathrm{CRE}_{\mathrm{PG}}\right)$ and of the adjacent putative CRE site (CRE-like1) led to a dramatic inhibition of the promoter responsiveness to peptones. Over expression of a dominant-negative mutant of CREB or of PKA produced a comparable and selective inhibitory effect on the activity of transfected promoter fragment containing the -350/-292 sequence. EMSA showed that CREB and fra2 transcription factors bound to $\mathrm{CRE}_{\mathrm{PG}}$ and CRE-like1 elements respectively, independently of peptone treatment.

Conclusions/interpretation. Our report identified cisand trans-regulatory elements implicated in the transcriptional control of $P G$ gene by nutrients in enteroendocrine cells. It highlights the role of a previously unsuspected CRE-like1 element, and emphasises the importance of CRE-related sequences in the regulation of $P G$ gene transcription in the intestine.

Keywords CREB - Enteroendocrine cells · fra2 . Glucagon-like peptides · Peptones · Proglucagon · Transcriptional regulation.
Received: 2 October 2003 / Accepted: 3 February 2004

Published online: 14 April 2004

C) Springer-Verlag 2004

M. Cordier-Bussat ( $\square)$

INSERM Unité 45, IFR 62, Faculté de Médecine RTH Laënnec, 7, rue G. Paradin, 69372 Lyon Cedex 08, France

E-mail: cordier@lyon.inserm.fr

Abbreviations: CaMK, calcium/calmodulin-dependent protein kinase $\cdot$ cAMP, $3^{\prime} 5^{\prime}$ cyclic adenosine monophosphate . CAP, CREB-associated protein - CCK, cholecystokinin · CRE, cAMP response element - CREB, CRE-binding protein . FSK, forskolin - GIP, glucose-dependent insulinotropic peptide · GLP, glucagon-like peptide · GRP, gastrin-releasing peptide $\cdot$ GUE, glucagon upstream enhancer · IBMX, isobutyl methyl xanthine $\cdot$ MAPK, mitogen-activated protein kinase $\cdot$ PepRE, peptone-response element · PG, proglucagon ·

PKA, cAMP-dependent protein kinase

\section{Introduction}

The proglucagon $(P G)$ gene is expressed by alpha cells of the islets of Langerhans, L cells located in the small and large intestine, and neurons of the central nervous system. Tissue-specific post-translational processing gives rise to different proglucagon-derived peptides. Intestinal L cells are the main source of glucagon-like peptides (GLPs) that display pleiotropic effects $[1,2]$. GLP-1 is a potent glucose-dependent insulinotropic hormone, contributes to glucose homeostasis, and inhibits food intake [1,2]. GLP-2 is mainly a trophic factor to intestinal epithelium [2]. The critical roles of gut-derived GLPs raised hope for their therapeutic use in several disorders, especially in Type 2 and Type 1 diabetes for GLP-1 [1, 2]. In this con- 
text, identifying the mechanisms that underlie GLPs synthesis and secretion is a major challenge.

It is well established that nutrients are physiological stimulants of GLPs secretion in vivo [1]. Nevertheless, only scarce information is available on the nutritional control of GLPs synthesis and especially of $P G$ gene transcription. Re-feeding after fasting [3, 4], ingestion of dietary fibres $[4,5,6]$ and jejunal infusion of long-chain triglycerides [3] were shown to increase the $P G$ mRNA content in rodent intestine at least in part through an increase of the transcription rate. We have shown previously that protein hydrolysates (i.e. peptones, which are a representative model of the intestinal luminal dietary protein content) induced a strong stimulation of GLP-1 secretion in rat jejunoileum and colon as well as in enteroendocrine STC-1 cells $[7,8]$. Using this latter model, we showed that exposure to peptones also increased $P G$ gene transcription [8], but via molecular pathways that remained to be characterised.

The mechanisms that govern $P G$ gene transcription in intestinal cells are poorly understood as compared with those in pancreatic cells [9]. The functional role of $\mathrm{G} 1$ and $\mathrm{G} 3$ proximal promoter elements via the binding of pax 6 and cdx $2 / 3$ transcription factors has been confirmed in intestinal cells $[10,11]$. It was also demonstrated that intestinal expression of the $P G$ gene in transgenic mice was dependent on a sequence located between -2300 and -1300 bp upstream of the transcription start site and containing a non-characterised glucagon upstream enhancer (GUE) [12, 13]. Beside nutrients, gastrin-releasing peptide (GRP) was the single previously identified stimulant of $P G$ promoter activity in intestinal cells. The canonical cAMP response element (CRE) localised from -298 to -292 was implicated in this stimulation although precise mechanisms and associated transcription factors were not definitively identified [14].

The aim of the present work was to identify cisand trans-regulatory factors involved in the peptoneinduced stimulation of $P G$ gene transcription in STC1 enteroendocrine cells. This cell line has been shown to be a valuable model to study GLP-1 secretion and intestinal PG gene transcription, as shown by several studies $[14,15,16,17]$. In STC-1 cells as in native intestinal endocrine cells, hormone release is increased by several agents, in particular those that induce membrane depolarisation and increase cAMP and calcium cytosolic contents. Using transient transfection experiments of PG promoter fragments with $5^{\prime}$ deletions or site-directed mutations, two cis-regulatory elements required for the full transcriptional effect of peptones were localised. Transcription factors bound to these sequences were also identified.

\section{Materials and methods}

Materials. Cell culture reagents were purchased from Invitrogen (Cergy-Pontoise, France). Peptones (enzymatic hydrolysate from meat, type I), forskolin and isobutyl methyl xanthine (IBMX) were from Sigma (Saint Quentin Fallavier, France).

The following plasmids were used: pGL3basic (Promega, Charbonnières, France) was the vector used for the cloning of the different $P G$ promoter constructs; pHRL-TK (Promega) was used as an internal standard for transfection efficiency. The pRc/CMV500/A-CREB vector overexpressing a dominant-negative mutant of CREB [18] and the MT-REV(AB) vector overexpressing a dominant-negative mutant of the protein kinase A (PKA) regulatory subunit [19] were kindly provided by Dr. C. Vinson (National Cancer Institute, Bethesda, Mass., USA) and Dr. G. S. McKnight (University of Washington, Seattle, Wash., USA) respectively. Oligonucleotides were purchased from Invitrogen.

Cloning of the PG promoter fragments and site-directed mutagenesis. A DNA fragment containing the first 2300 bp upstream of the rat $P G$ gene transcription start site was excised from the pBluescript vector and inserted into the polylinker of the pGL3basic vector, upstream of the firefly luciferase reporter gene. Appropriate enzymatic digestions followed by ligations were performed to generate shorter promoter constructs of $-2286,-1760,-1391$ and -689 bp respectively. The -350 , -292 and -136 bp promoter fragments were obtained by direct subcloning of SacI promoter fragments [20] excised from a pOCAT vector and introduced into the pGL3basic vector.

Site-directed mutagenesis experiments in $\mathrm{CRE}_{\mathrm{PG}}$ and $\mathrm{CRE}$ like elements of the $P G$ promoter were carried out using the QuikChange kit (Stratagene, Amsterdam, The Netherlands) according to the manufacturer's instructions. Briefly, the $1760 \mathrm{bp}$ promoter construct was denatured and hybridised with an oligonucleotide containing the desired mutation prior to amplification by polymerase chain reaction (14 cycles as follows: $30 \mathrm{~s}, 95^{\circ} \mathrm{C} / 1 \mathrm{~min}, 55^{\circ} \mathrm{C} / 14 \mathrm{~min}, 68^{\circ} \mathrm{C}$ ). The following oligonucleotides were used:

CRE $_{\mathrm{PG}}$ mut (-312/-268), CTCTAGGCTCATTGTCATGCAAAATTCACTTCAGAG;

CRE-like1mut (-332/299), CAAGACCCTCAAAGTCAGACTCTAGGCTCATTTG;

CRE-like2mut (-571/-536), CTATCAGCATCAGGTCATGTGGGTATTCTCATTTTG;

CRE-like3mut (-1399/-1372), TATACAGCTGGGAATGCAGCCTAATCTG;

CRE-like4mut (-1427/-1389), CACCAATGAGAAAGGTCCGGAGATAATTTATACAGCTG CRE-like5mut (-1624/1588), GTAAAGGTGTGGCGTCACAACGGTCGCAGTCATAAAG. The $\mathrm{CRE}_{\mathrm{PG}}$ mut/CRElike1mut double mutant was obtained using the pGL3basic/pGluc $\mathrm{CRE}_{\mathrm{PG}}$ mut plasmid as a template for the second mutation. XL1-Blue competent bacteria strains were then transformed by each amplified plasmid. All mutations were checked by DNA sequencing.

Cell culture and transfection experiments. STC-1 cells are derived from an intestinal endocrine tumour developed in a double transgenic mouse expressing the simian virus 40 large $\mathrm{T}$ antigen and the polyoma virus small $t$ antigen under the control of the rat insulin promoter [21]. Cells were grown in RPMI1640 medium supplemented with $5 \%$ (vol/vol) fetal calf serum (FCS), $2 \mathrm{mmol} / \mathrm{l}$ glutamine and antibiotics (100 IU penicil$\mathrm{lin} / \mathrm{ml}$ and $50 \mu \mathrm{mol} / \mathrm{l}$ streptomycin) in a humidified $\mathrm{CO}_{2}$ :air (5\%:95\%) incubator at $37{ }^{\circ} \mathrm{C}$.

Transfection experiments were done by using the ExGen transfection reagent (EuroMedex, Mundolsheim, France), ac- 
cording to the manufacturer's instructions. Briefly, 2 days before transfection, STC-1 cells were seeded into 48-well plates at a density of 40000 cells/well. For each well, $0.25 \mu \mathrm{l}$ ExGen reagent was mixed with $125 \mathrm{ng} P G$ gene reporter plasmid in $150 \mathrm{mmol} / \mathrm{l} \mathrm{NaCl}$. In all transfection experiments, a plasmid with a renilla reporter gene under the control of a thymidine kinase promoter (pHRL-TK, $6.25 \mathrm{ng} /$ well) was used as an internal control to normalise results. In cotransfection experiments with pRc/CMV500/A-CREB or MT-REV(AB) plasmids, the corresponding empty vectors pRc/CMV500 or pUC13 were added to each set of transfections to ensure that each well received the same amount of DNA, and the DNA:Exgen ratio was maintained constant (375 ng:0.75 $\mu \mathrm{l}$ ). The Exgen-plasmid DNA mixture was added to each well for $5 \mathrm{~h}$ at $37^{\circ} \mathrm{C}$, then replaced with fresh complete medium for an additional 24-h period before treatment. RPMI complete medium was then replaced with RPMI without FCS but containing $0.2 \% \mathrm{BSA}$ in the presence or absence of peptones $2 \%$ (wt/vol). After a 16-h incubation at $37{ }^{\circ} \mathrm{C}$, cells were harvested in lysis buffer, and firefly luciferase and renilla luciferase were measured using the Dual Luciferase Reporter assay system (Promega) in accordance with the manufacturer's instructions. All results were expressed as relative firefly/renilla luciferase activities. Untreated conditions were all normalised to 1 and peptone-treated conditions were expressed as fold inductions.

Electrophoresis mobility shift assay. Nuclear extracts from STC-1 cells were prepared according to the method of [22]. Sequences of the oligonucleotides corresponding to CRE $\left(\mathrm{CRE}_{\mathrm{PG}},-312 /-268 \mathrm{bp}\right)$ and CRE-like1 (-332/-299 bp) elements were CTCTAGGCTCATTTGACGTCAAAATTCACTTCAGAG and CAAGACCCTCAAATGACTCCTCTAGGCTCATTTG respectively. Sequences of the other oligonucleotides used were as follows: consensus CRE from the somatostatin promoter [23] (CRESMS), AGAGATTGCCTGACGTCAGAGAGCTAG; peptone response element from the cholecystokinin $(C C K)$ promoter (PepRE) [24], CGGACTGCGTCAGCACTGGGG; AP1 consensus sequence (Promega), CGCTTGATGAGTCAGCCGGAA. Radiolabelling of oligonucleotides used as probe was done by using T4 polynucleotide kinase (Promega) with $\left[\gamma^{32} \mathrm{P}\right]$-ATP $(187000 \mathrm{MBq} / \mathrm{mmol}, 374 \mathrm{MBq} / \mathrm{ml}$, Amersham Pharmacia Biotech, Orsay, France) and followed by polyacrylamide gel electrophoresis purification. Nuclear extracts (10 to $20 \mu \mathrm{g}$ protein) were incubated for $10 \mathrm{~min}$ at $4{ }^{\circ} \mathrm{C}$ in a standard binding mix containing $10 \mathrm{mmol} / \mathrm{l}$ Tris, $4 \%$ glycerol, $1 \mathrm{mmol} / 1 \mathrm{MgCl}_{2}, 0.5 \mathrm{mmol} / \mathrm{l}$ EDTA, $50 \mathrm{mmol} / \mathrm{l} \mathrm{NaCl}$, $1 \mu \mathrm{g}$ polydIdC, $1 \mu \mathrm{g}$ polydAdT, $10 \mathrm{mmol} / \mathrm{l} \mathrm{DTT}, \mathrm{pH}$ 7.6. The radiolabelled probe $(40000 \mathrm{cpm})$ was then added in the binding reaction and the mixture was incubated for $20 \mathrm{~min}$ at room temperature before migration on a $4 \%$ polyacrylamide/ $0.5 \times \mathrm{TBE}$ gel at $4{ }^{\circ} \mathrm{C}$. $\mathrm{KCl}(75 \mathrm{mmol} / \mathrm{l})$ was added in gels for experiments with the $\mathrm{CRE}_{\mathrm{PG}}$ oligonucleotide. The gel was then dried and subjected to autoradiography. In competition experiments, an excess of cold oligonucleotide was added to the standard reaction $20 \mathrm{~min}$ prior to the radiolabelled probe. In experiments using antibodies, $2 \mu \mathrm{l}$ of pure antibody were added to the standard reaction and incubated for $90 \mathrm{~min}$ at $4{ }^{\circ} \mathrm{C}$ before the probe was added. Antibodies used were purchased from Santa Cruz Biotechnology (Tebu, Le Perray-en-Yvelines, France): anti-CREB-1 (sc-186X) cross-reactive with CREB-1, ATF-1 and CREM-1; anti-ATF-1 (sc-243X); anti-fos (sc253X) cross-reactive with c-fos, fos B, fra1 and fra2; anti-fosB (sc-48X); anti-fra1 (sc-605X) and anti-fra2 (sc-171X).

Data analysis. All results are presented as the mean \pm SEM. Data were analysed by ANOVA followed by post hoc Stu- dent's $t$ test. Differences between two means with a $p$ value less than 0.05 were regarded as significant.

\section{Results}

The $P G$ promoter region spanning -350 to $-292 \mathrm{bp}$ is crucial to confer peptone responsiveness. To localise cis-regulatory elements critical for the transcriptional response to peptones, a series of $5^{\prime}$-deleted $P G$ promoter fragments was fused upstream of the luciferase reporter gene in the pGL3basic vector. Seven constructs were generated with fragments progressively deleted in their $5^{\prime}$ extremity to progressively eliminate the GUE (between -2300 and $-1300 \mathrm{bp}$ ), several putative CREs (CRE-like), the canonical CRE (dubbed here $\mathrm{CRE}_{\mathrm{PG}},-298 /-292 \mathrm{bp}$ ) as well as the more proximal G3, G2 and G5 elements (Fig. 1). STC-1 cells were transiently transfected with these constructs before treatment with peptones $2 \%(\mathrm{wt} / \mathrm{vol})$ and measurement of luciferase activities.

As shown in Figure 1a,b, peptones induced an average eightfold stimulation of the $P G$ promoter activity as compared to control when using promoter fragments with their $5^{\prime}$ extremities lying from -2286 to $689 \mathrm{bp}$. The stimulatory effect of peptones decreased step by step using shorter promoter fragments. The deletion of the sequence from -689 to $-350 \mathrm{bp}$ (named Pep reg1 in Fig. 1) correlated with a decrease of about $20 \%$ of the promoter stimulation $(6.13 \pm 0.69$ vs $7.61 \pm 0.64$-fold induction, $n=6, p<0.05$ ). Remarkably, the next deletion from -350 to -292 bp (Pep reg 2 sequence) correlated with a decrease of $50 \%$ of the -350 promoter fragment stimulation $(3.08 \pm 0.25$ vs $6.13 \pm 0.69$-fold induction, $n=6, p<0.05$ ). Finally, the last deletion from -292 to -136 bp (Pep reg3 sequence) led to a decrease of $25 \%$ of the -292 fragment stimulation to reach a $2.25 \pm 0.12$-fold residual stimulation. We conclude that peptones stimulate $P G$ gene transcription via several promoter regions localised in the first $689 \mathrm{bp}$. The region Pep reg2 between -350 and -292 bp contains the main peptone response element(s). This region encompasses the previously described cAMP responsive element $\left(\mathrm{CRE}_{\mathrm{PG}}\right)$ of the PG gene promoter [9]. Since we demonstrated that peptones evoked cAMP production and PKA stimulation in STC-1 cells [25], the transcriptional effects of peptone and forskolin treatments on p350 and p292 promoter fragments were assessed comparatively.

As shown in Figure 1c, activation of the cAMP pathway by forskolin/IBMX $\left(10^{-5} \mathrm{~mol} / \mathrm{l} / 5 \times 10^{-4} \mathrm{~mol} / \mathrm{l}\right)$ induced an eight- to ninefold stimulation of the -350 promoter fragment, comparatively with peptones that induced a five- to sixfold stimulation. Significant reduction of both forskolin/IBMX and peptone effects on the -350 construct was obtained when overexpressing of a dominant-negative mutant of the PKA regulatory subunit [MT-REV(AB)]. Deletion of the 
a

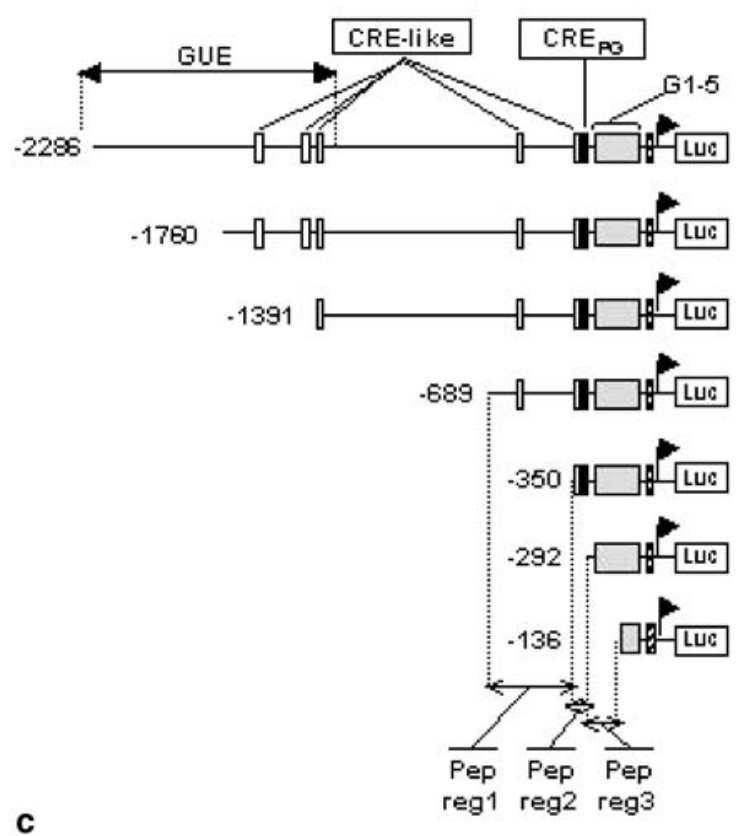

b
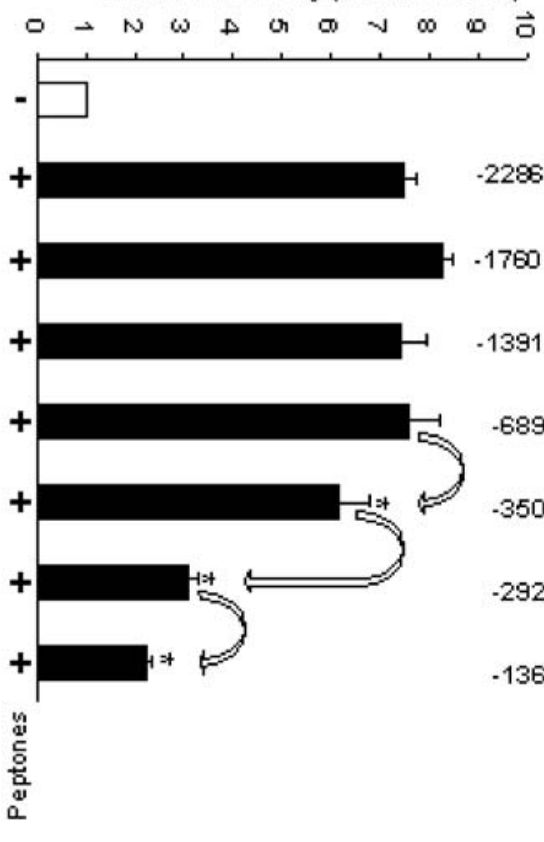

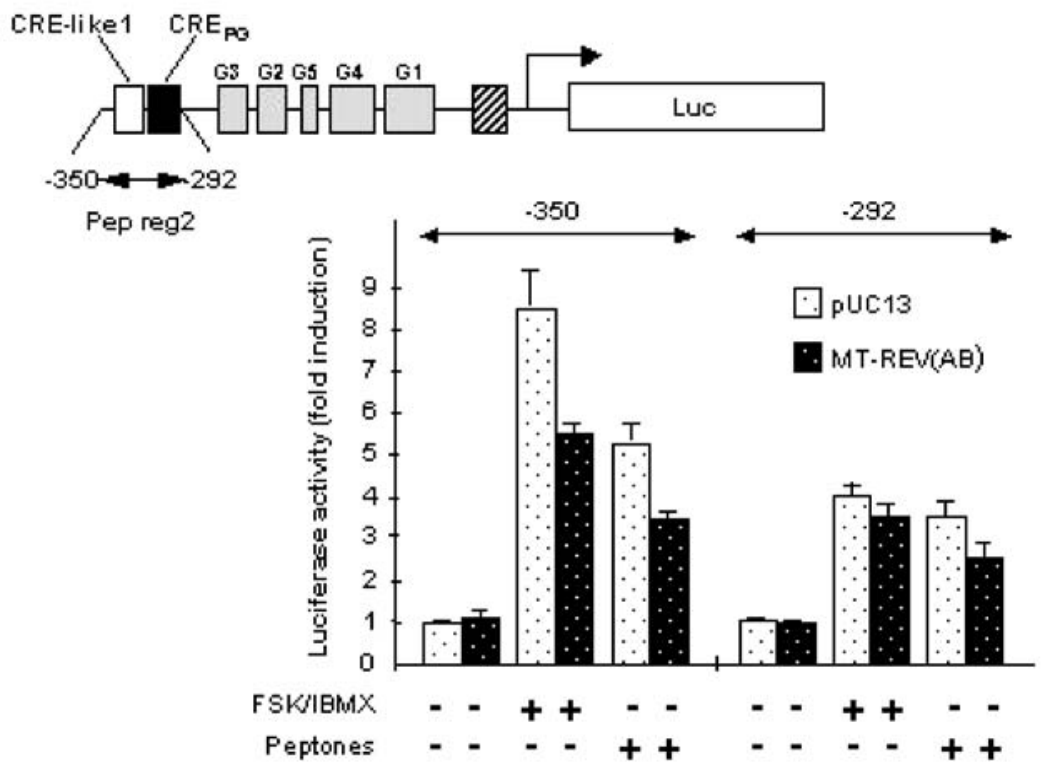

Fig. 1. Effect of the serial $5^{\prime}$-deletion of the $P G$ promoter on its ability to respond to peptones. a. Schematic diagram of the different $P G$ promoter constructs: a series of promoter fragments with progressive $5^{\prime}$ deletions was subcloned upstream of the luciferase reporter gene in the pGL3basic vector. Putative CRE-like elements and the previously described CRE $\left(\mathrm{CRE}_{\mathrm{PG}}\right)$ are indicated by white and black rectangles respectively. b. STC-1 cells were transfected with the different promoter constructs and incubated for $16 \mathrm{~h}$ in the presence $(+$, black bars) or absence $(-$, white bar) of peptones $2 \%(\mathrm{wt} / \mathrm{vol})$ before measurement of the luciferase activities. Results, expressed as described in 'Materials and methods', represent the mean $\pm \mathrm{SEM}$ of at least four independent experiments, each per- formed in triplicate. $* p<0.05$ versus the immediate longer fragment. The white bar symbolises the untreated control values normalised to 1 for each promoter tested. c. Comparative transcriptional effects of peptones and forskolin on $P G$ promoter fragments: STC-1 cells were transiently cotransfected with the -350 or $-292 P G$ promoter constructs (see the closer view of the first $-350 \mathrm{bp}$ region) and the MT-REV(AB) vector overexpressing a dominant-negative mutant of the protein kinase $\mathrm{A}$ (PKA) regulatory subunit or the corresponding empty vector (pUC13). Transfected cells were then either treated or not with forskolin (FSK)/IBMX $\left.\left[\left(10^{-5} \mathrm{~mol} / \mathrm{l}\right) / 5 \times 10^{-4} \mathrm{~mol} / \mathrm{l}\right)\right]$ or peptones $2 \%(\mathrm{wt} / \mathrm{vol})$ 
a

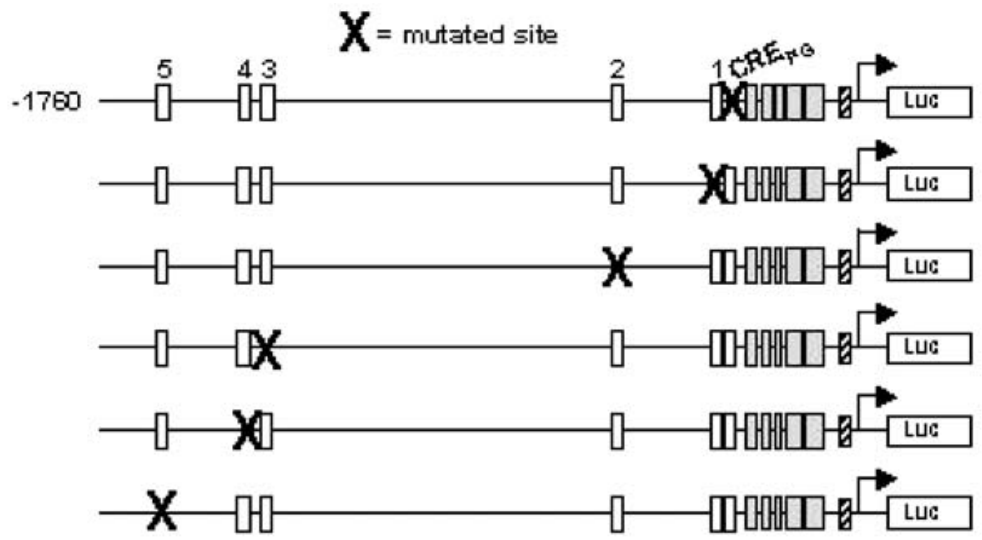

b
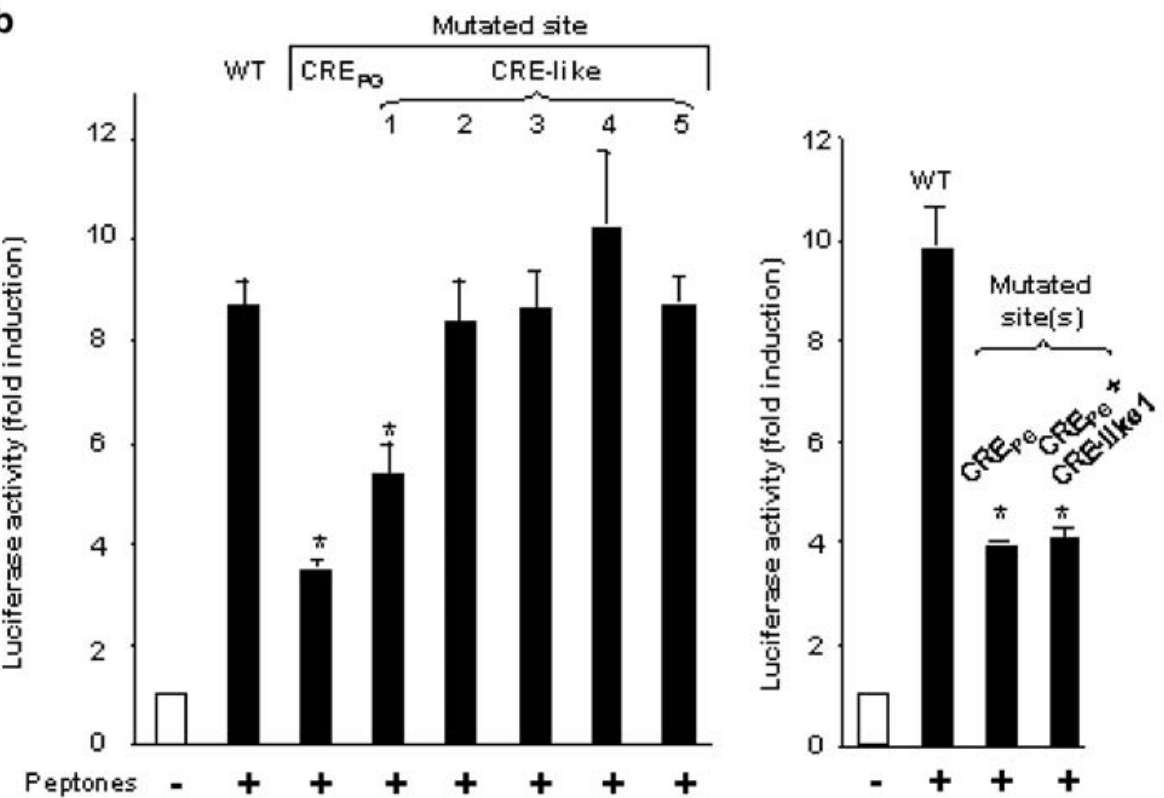

Fig. 2. Effect of the invalidation of the different CRE-related elements on the peptone-induced stimulation of $P G$ promoter activity. a. Schematic diagram of the different mutated constructs generated from the $-1760 \mathrm{bp}$ wild-type (WT) $P G$ promoter fragment by site-directed mutagenesis. CRE-like elements detected by computer analysis are numbered from 1 to 5 from $3^{\prime}$ to $5^{\prime}$. The previously described $\mathrm{CRE}_{\mathrm{PG}}$ element is the only one that shares a $100 \%$ homology with the consensus CRE sequence. b. STC-1 cells were transfected with the different mutated $P G$ promoter constructs and then incubated for 16 $\mathrm{h}$ in the presence (+) or absence (-) of peptones $2 \%(\mathrm{wt} / \mathrm{vol})$ before measurement of luciferase activities. Results, expressed as described in 'Materials and methods', represent the mean \pm SEM of at least three independent experiments, each performed in triplicate. ${ }^{*} p<0.05$ versus the WT promoter fragment. The white bar symbolises the untreated control values normalised to 1 for each promoter tested

Pep reg2 sequence was associated with a decrease of both forskolin/IBMX- and peptone-induced transcriptional stimulation. This suggests that peptones and forskolin exert their transcriptional effect on the $P G$ promoter at least in part through overlapping elements located in the Pep reg2 sequence. We therefore decided to focus on this region.

Two CRE-related elements are required for the peptone effect. Since peptones were shown to evoke cAMP production, PKA stimulation and CREB phosphorylation in STC-1 cells [25], and since cAMP/ PKA pathways are often directed toward CRE-like sequences, we evaluated the role of such sequences in the peptone-induced stimulation of PG promoter. The region located between -350 and $-292 \mathrm{bp}$ encompasses two sites whose sequences are related to the CRE consensus site primarily described in the somatostatin promoter [23]. The first one (-298 bp/-292 bp) was the previously described $\mathrm{CRE}_{\mathrm{PG}}$ consensus site (TGACGTCA) [9]. The second one $(-319 \mathrm{bp} /-312 \mathrm{bp})$, here named CRE-like1 (TGACTCCT), shared partial homology with the canonical CRE. Computer analysis also showed the presence of four other CRE-related elements (termed CRE-like2 to CRE-like5 from $3^{\prime}$ to $5^{\prime}$ ) along the first $2300 \mathrm{bp}$ of the rat $P G$ promoter (Fig. 1a and $2 \mathrm{a}$ ). To investigate the relevance of these CRE-related elements in the transcriptional regulation of the $P G$ gene upon peptone treatment, we analysed the functional consequences of site-directed mutations on peptoneinduced transcriptional activation. 
The six mutated promoter fragments and the wildtype counterpart were transiently transfected in STC-1 cells followed by treatment with or without peptones. We observed that mutation of the $\mathrm{CRE}_{\mathrm{PG}}$ or CRElike1 elements abolished $68 \%$ and $43 \%$ of the peptone-induced stimulation of promoter activity respectively (Fig. 2b, left). The basal promoter activity was not affected by these mutations (data not shown), as previously described [26, 27, 28]. Remarkably, the $\mathrm{CRE}_{\mathrm{PG}} / \mathrm{CRE}$-like1 double mutation induced the same decrease of transcriptional stimulation as the single $\mathrm{CRE}_{\mathrm{PG}}$ one, suggesting a prominent function of this latter element (Fig. 2b, right). Moreover, mutation of the other CRE-like elements did not modify the transcriptional response to peptones. We conclude that the two adjacent $\mathrm{CRE}_{\mathrm{PG}}$ and CRE-like1 DNA elements play crucial roles in the peptone responsiveness of the PG promoter.

A-CREB overexpression inhibits peptone-induced transcriptional stimulation via CREPG. Since $\mathrm{CRE}_{\mathrm{PG}}$ was previously described to bind recombinant CREB protein in vitro [26], and since peptones elicited CREB phosphorylation in STC-1 cells [25], we decided to assess the functional role of CREB transcription factor in the peptone-induced stimulation of $P G$ promoter. For this purpose a dominant-negative CREB protein (ACREB), previously described to specifically impair CREB binding to DNA [18], was overexpressed in STC-1 cells in transient cotransfection experiments with a series of promoter constructs (Fig. 3).

The cotransfection of A-CREB expression vector, but not that of its empty vector counterpart, was associated with a 60 to $65 \%$ inhibition of the peptone-induced stimulation of $-1760 \mathrm{bp}$ and $-350 \mathrm{bp}$ promoter fragments activity (residual inductions of $3.25 \pm 0.25$ vs 7.82 \pm 0.30 -fold, $n=6$ and $3.01 \pm 0.39$ vs $6.86 \pm 0.86$ fold, $n=4$, respectively, $p<0.05$ ) (Fig. 3a). A-CREB did not exert any inhibitory effect on -292 bp or 136 bp $P G$ promoter constructs. Since CRE-like2 to 5 located between -1760 and -350 bp were obviously not implicated in the transcriptional stimulation by peptones, these results strongly suggested an implication of CREB through its binding on promoter sequences between -350 and $-292 \mathrm{bp}$, mainly CRElike1 and $\mathrm{CRE}_{\mathrm{PG}}$ sequences. As shown in Figure 3b, the overexpression of A-CREB inhibited the peptoneinduced stimulation of CRE-like1mut promoter construct but did not alter the residual simulation of $\mathrm{CRE}_{\mathrm{PG}}$ mut construct.

Altogether the data suggested that peptones induced stimulation of $P G$ gene transcription via mechanisms dependent on CREB transcription factor DNA binding, through the region located between $-350 \mathrm{bp}$ and $-292 \mathrm{bp}$. Moreover, the differential effect of A-CREB on the two CRE-related sequences suggests that $\mathrm{CREB}$ might bind to $\mathrm{CRE}_{\mathrm{PG}}$ and not to CRElike1. We then tested this hypothesis.
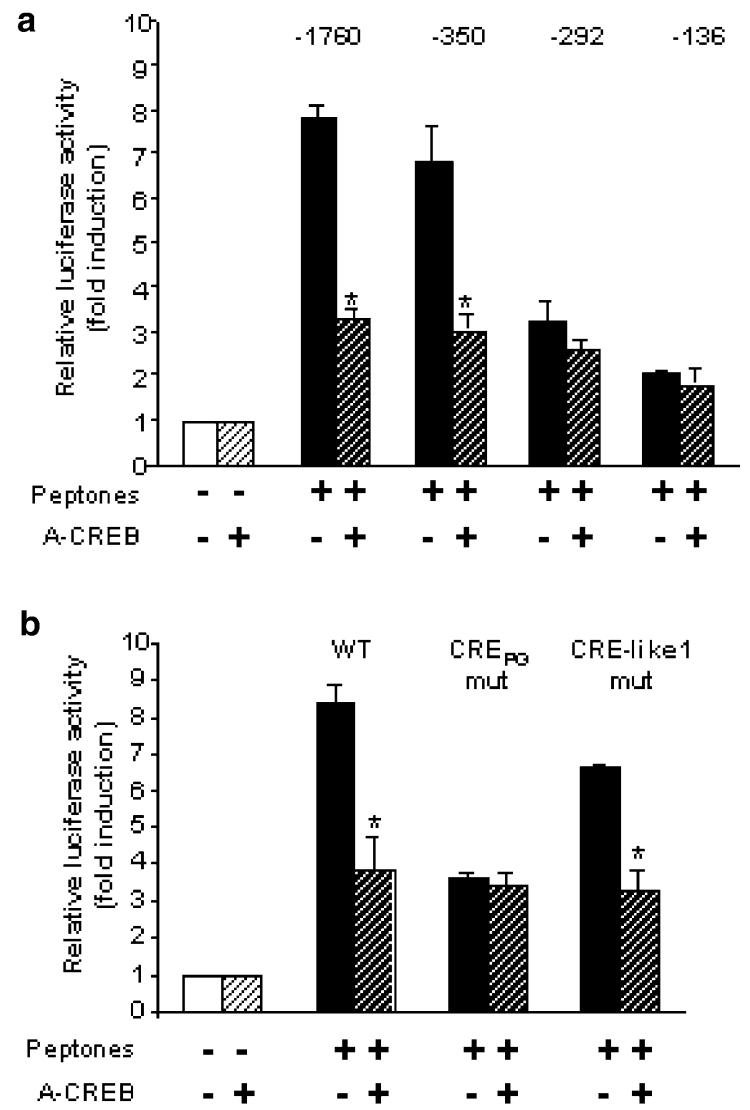

Fig. 3. Effect of A-CREB overexpression on the peptone-induced stimulation of the $P G$ promoter activity. STC-1 cells were cotransfected with a vector overexpressing a dominant-negative mutant of CREB (A-CREB, $250 \mathrm{ng}$ ) and with either (a) different fragments of the $P G$ promoter or (b) the $-1760 \mathrm{bp}$ fragment, either wild-type (WT) or mutated on the $\mathrm{CRE}_{\mathrm{PG}}$ sequence $\left(\mathrm{CRE}_{\mathrm{PG}} \mathrm{mut}\right)$ or on the $\mathrm{CRE}$-like1 sequence (CRE-like1mut). Cells were then incubated for $16 \mathrm{~h}$ in the presence $(+)$ or absence $(-)$ of peptones $(2 \% \mathrm{wt} / \mathrm{vol})$ and luciferase activities were measured. Results, expressed as described in 'Materials and methods', represent the mean \pm SEM of at least three independent experiments, each performed in triplicate. ${ }^{*} p<0.05$ versus the corresponding stimulated conditions without A-CREB. The white bar symbolises the untreated control values normalised to 1 for each promoter fragment tested

The CREPG element functions as a low-affinity binding site for intestinal nuclear factors. To characterise the transcription factors binding to $\mathrm{CRE}_{\mathrm{PG}}$ and CRElike1, EMSA were performed. Representative results obtained using the $\mathrm{CRE}_{\mathrm{PG}}$ oligonucleotide as a probe are shown (Fig. 4). A single specific protein/DNA complex (C1) was detected in the presence of $10 \mu \mathrm{g}$ of STC-1 nuclear extracts either treated or not with peptones. The binding of $\mathrm{C} 1$ complex was progressively inhibited by the addition of increasing quantities (5-, 25- and 125-fold excess) of cold $\mathrm{CRE}_{\mathrm{PG}}$ oligonucleotide to the binding reaction, whereas equivalent amounts of cold $\mathrm{CRE}_{\mathrm{PG}}$ mut oligonucleotide had no effect (Fig. 4a). The peptone-response element 
a

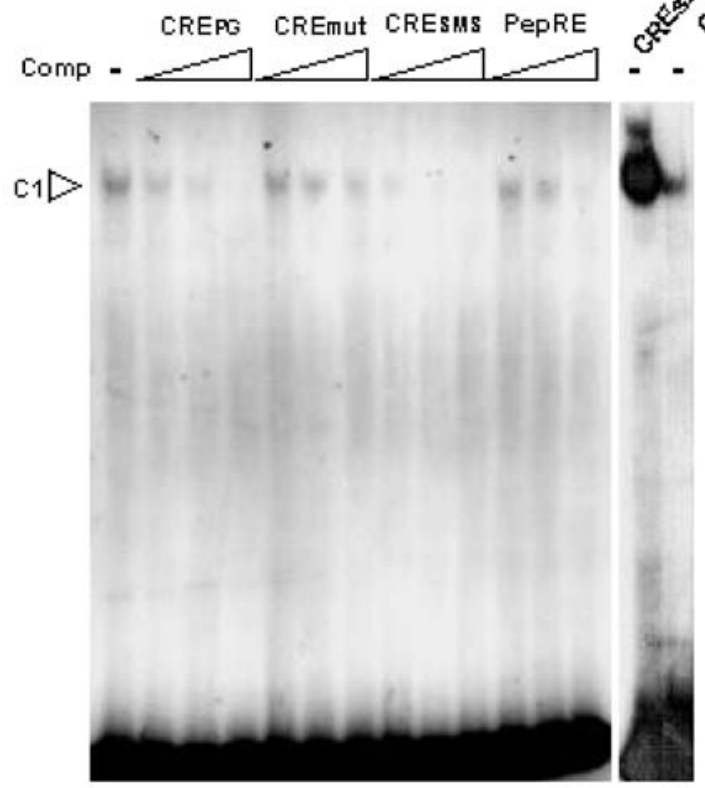

C

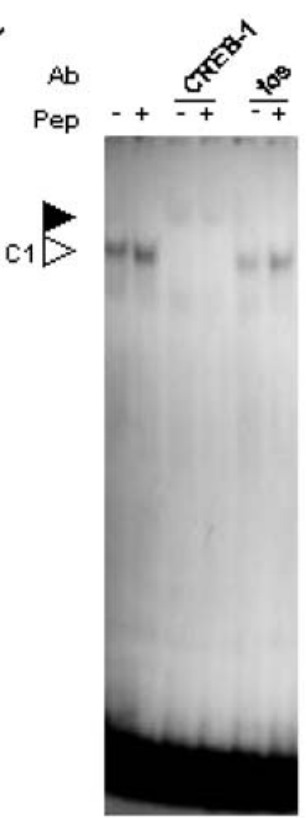

Fig. 4. Characterisation of a protein complex binding to the $\mathrm{CRE}_{\mathrm{PG}}$ element and identification of the bound transcription factors. EMSA were done by using a $\mathrm{CRE}_{\mathrm{PG}}$ oligonucleotide as probe and $10 \mu \mathrm{g}$ STC-1 cell nuclear extracts. a. Competition experiments were carried out in the presence of increasing amounts (1, 5 and $25 \mathrm{ng}$ ) of cold oligonucleotides: $\mathrm{CRE}_{\mathrm{PG}}$, $\mathrm{CRE}_{\mathrm{PG} \text { MUT }}$ (same mutation as described in Fig. 2), CRE $\mathrm{SMS}_{\mathrm{S}}$ (encompassing the CRE consensus sequence from the somatostatin promoter) and PepRE (from the $C C K$ promoter). b. Binding of STC-1 nuclear extracts to the radiolabelled $\mathrm{CRE}_{\mathrm{SMS}}$ oligonucleotide used as a probe (lane 1) in comparison with the $\mathrm{CRE}_{\mathrm{PG}}$ probe (lane 2). c. Nuclear extracts from STC-1 cells either treated (+) or not (-) with peptones $2 \%$ (wt/vol) were incubated with antibodies raised against various transcription factors as indicated, prior to the incubation with the radiolabelled $\mathrm{CRE}_{\mathrm{PG}}$ probe. The protein/DNA complex (C1) and the supershifted band are indicated by white and black arrows respectively. Results are representative of three independent experiments

(PepRE) of the $C C K$ promoter [24] was previously described to bind CREB protein. A 125 -fold excess of PepRE oligonucleotide also inhibited the binding of the $\mathrm{C} 1$ complex. Remarkably, only a fivefold excess of cold $\mathrm{CRE}_{\mathrm{SMS}}$ oligonucleotide, corresponding to the consensus CRE element of the somatostatin promoter, was sufficient to completely inhibit the binding of $\mathrm{C} 1$ complex, suggesting that nuclear factors in the $\mathrm{C} 1$ complex exhibited a higher affinity for the $\mathrm{CRE}_{\mathrm{SMS}}$ element than for the $\mathrm{CRE}_{\mathrm{PG}}$. Identical results were obtained using both nuclear extracts of STC-1 cells either treated or not with peptones. Using the $\mathrm{CRE}_{\mathrm{SMS}}$ radiolabelled probe in a binding reaction with an equivalent amount of STC-1 nuclear extracts, a complex migrating at the same position as $\mathrm{C} 1$ was detected but with an eminently greater intensity, emphasis- ing that STC-1 nuclear proteins had a higher affinity for the $\mathrm{CRE}_{\mathrm{SMS}}$ than for the $\mathrm{CRE}_{\mathrm{PG}}$ element (Fig. 4b).

To assess the presence of CREB transcription factor in the $\mathrm{C} 1$ complex, binding experiments were carried out in the presence of antibodies using the $\mathrm{CRE}_{\mathrm{PG}}$ probe and nuclear extracts from STC-1 cells either treated or not with peptones. As shown in Figure 4c, incubation of nuclear extracts with the anti-CREB-1 antibody completely inhibited the binding of $\mathrm{C} 1 \mathrm{com}-$ plex, in contrast with the anti-fos antibody incubation which had no effect. The same results were obtained using nuclear extracts of STC-1 cells either treated or not with peptones. These data show that the $\mathrm{CRE}_{\mathrm{PG}}$ element is able to bind nuclear proteins present in STC1 cells, including members of the CREB family. This is in agreement with the previously observed effect of $\mathrm{A}-\mathrm{CREB}$ on this sequence.

The CRE-like1 element binds nuclear factors different from those bound to the CREPG. The same approach was used in an attempt to characterise the nuclear factors binding to the CRE-like1 element. Two complexes, C2 and C3, were observed when the radiolabelled CRE-like1 oligonucleotide was incubated with $20 \mu \mathrm{g}$ of nuclear extracts from STC-1 cells (Fig. 5). The binding of $\mathrm{C} 2$ and $\mathrm{C} 3$ was inhibited by adding a 125fold excess of cold CRE-like1 oligonucleotide to the reaction whereas none of the other competitors including CRElike1mut but also $\mathrm{CRE}_{\mathrm{SMS}}$, PepRE and AP1 cold oligonucleotides was able to impair $\mathrm{C} 2$ and $\mathrm{C} 3$ binding (Fig. 5a).

Experiments using antibodies were then performed. Incubation of STC-1 nuclear extracts with anti-CREB and anti-ATF-1 antibodies before adding the probe to the binding reaction had no effect on $\mathrm{C} 2$ and $\mathrm{C} 3$ formation (Fig. 5b). Conversely, an anti-fos antibody 
a

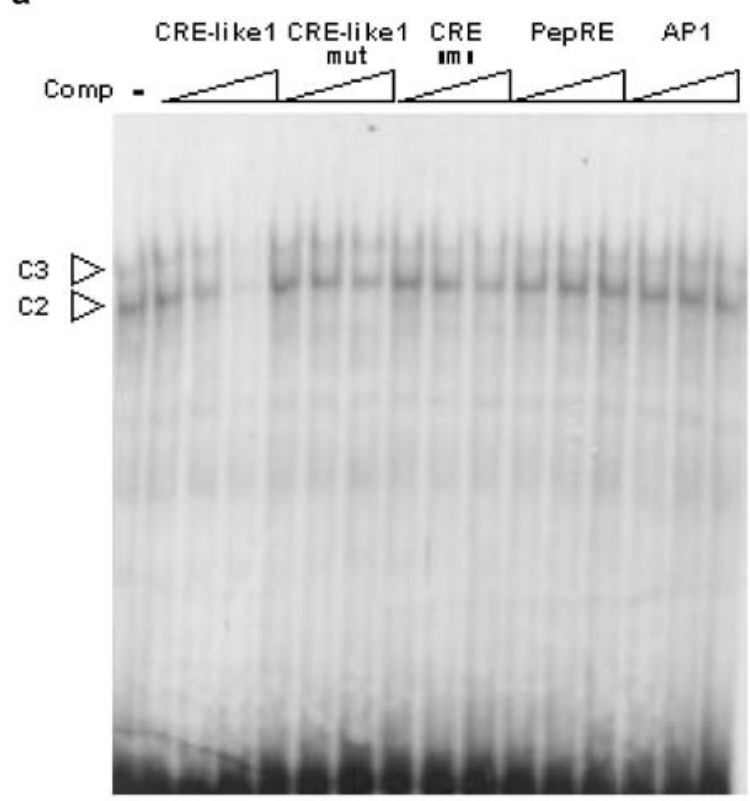

b

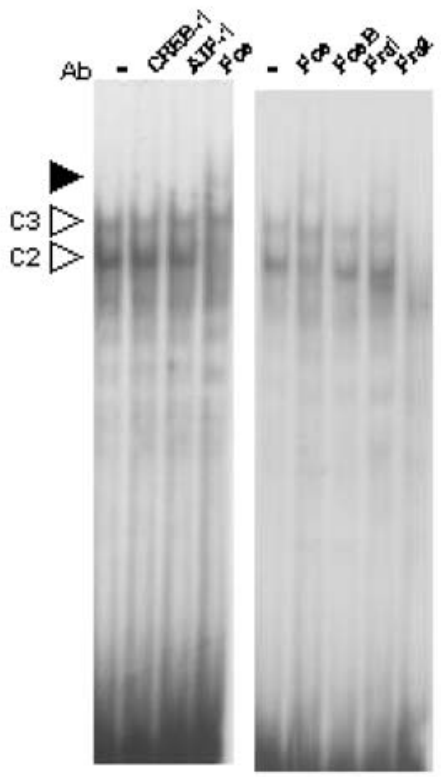

Fig. 5. Characterisation of protein complexes binding to the CRE-like1 element and identification of the bound transcription factors. EMSA were done by using a CRE-like1 oligonucleotide as probe and $20 \mu \mathrm{g}$ STC-1 cell nuclear extracts. a. Competition experiments were carried out in the presence of increasing amounts (1, 5 and $25 \mathrm{ng}$ ) of cold oligonucleotides: CRE-like1, CRE-like1mut (same mutation as described in Fig. 2), $\mathrm{CRE}_{\mathrm{SMS}}$, PepRE and AP1 (consensus sequence for AP1 binding site). b. Nuclear extracts from STC-1 cells were incubated with antibodies raised against various transcription factors as indicated, prior to incubation with the radiolabelled CRE-like1 probe. The protein/DNA complexes (C2 and C3) and the supershifted band are indicated by white and black arrows respectively. Results are representative of three independent experiments

made the $\mathrm{C} 2$ complex partially disappear and shift to a higher molecular weight band (see black arrow, Fig. 5b). The anti-fos antibody used is broadly reactive with different members of the fos family; we therefore tested specific anti-fosB, anti-fral and antifra 2 antibodies. Only anti-fra 2 antibody prevented the formation of $\mathrm{C} 2$ and $\mathrm{C} 3$ complexes (Fig.5b). The same results were obtained using nuclear extracts of STC-1 cells either treated or not with peptones (not shown). We conclude that the CRE-like1 element does not bind CREB but bound fra2. Here again, this result is in agreement with the previous data showing that the mutation of CRE-like1 does not impair A-CREB inhibitory effect on the $P G$ promoter.

\section{Discussion}

The indisputable importance of gut-derived GLPs in the control of glucose homeostasis and intestinal func- tion $[1,2]$ has fostered interest in their therapeutic use in several disorders, diabetes in particular. Despite the physiological relevance of GLPs, the molecular mechanisms underlying nutrient-induced $P G$ gene transcription remain nearly unexplored. In this study, we characterised cis- and trans-regulatory DNA elements that mediate $P G$ promoter response to protein hydrolysates in STC-1 cells.

The $P G$ promoter region located between -350 and -292 bp was pointed out as the major target of peptone effect, via two CRE-related elements: the previously described $\mathrm{CRE}_{\mathrm{PG}}$ consensus sequence (TGACGTCA) [9] as well as the 10 bp-upstream CRE-like1 sequence (TGACTCCT), whose functional relevance had not been reported in the past. Previous experiments in pancreatic cells did show that the PG gene promoter from -291 to -298 contained a CRE sequence that mediates cAMP-dependent activation of gene transcription, which was abolished by specific mutations of the CRE [26, 27, 28]. This sequence was shown to bind recombinant CREB-327 bacterial protein [26]. In rat primary intestinal cells [29] as in several cell lines [15, 30] increased cAMP levels were shown to stimulate PG gene transcription. Remarkably, deletion of sequence from -298 to -254 overlapping the CRE sequence was not previously reported to eliminate the forskolin induction of the 5 -truncated glucagon CAT plasmid in the transfected STC-1 cells [15]. Furthermore, the forskolin induction was preserved after deletion of the sequences down to -60 , suggesting that basal transcription factors may be also activated by cAMP. Our study confirmed that the -292 promoter construct conserved both forskolin and peptone residual inducibility. Nevertheless, deletion of the sequence from -350 to -292 decreased both peptone and forskolin responsiveness of the corresponding $P G$ promoter-Lucifer- 
ase constructs. The reasons for these discrepancies are unclear.

We show that $\mathrm{CRE}_{\mathrm{PG}}$ and $\mathrm{CRE}$-like1 bind distinct transcription factors contained in STC-1 nuclear extracts. We confirmed that CREB transcription factor contained in STC-1 nuclear extracts can bind to $\mathrm{CRE}_{\mathrm{PG}}$. Moreover, impairment of CREB DNA-binding by overexpression of A-CREB dominant-negative protein in STC-1 cells dramatically reduced the peptone effect on $P G$ promoter activity, emphasising the requirement of this protein/DNA interaction to observe the peptone-induced transcriptional stimulation of $P G$ promoter. Conversely, CRE-like1 does not bind CREB but Fos-related antigen 2 (fra2). It is conceivable that CRE-like1 and $\mathrm{CRE}_{\mathrm{PG}}$ might not function independently since the double invalidation of those sequences did not result in an additive inhibition of the peptone effect. These two elements could co-operate through an interaction between CREB and fra2, mediated by their leucine zipper domains. The binding of multiprotein complexes containing CREB and fra2, or more generally CREB/ATF- and fos-family proteins, were reported to regulate transcriptional activity of different other genes [31, 32, 33]. Although $\mathrm{CRE}_{\mathrm{PG}}$ and somatostatin promoter CRE element [23] possess an identical sequence, STC-1 nuclear factors displayed a weaker affinity for $\mathrm{CRE}_{\mathrm{PG}}$. These differences could be attributed to the sequences flanking the core element. Indeed, a TCATT sequence is present between the $\mathrm{CRE}_{\mathrm{PG}}$ and CRE-like1 elements. Evidence was reported that CREB-associated proteins (CAPs) bound to TCATT sequences flanking the CRE octamer could inhibit CREB-mediated transcriptional stimulation in pancreatic cells [34]. We postulate that constitutive occupation of the CRE-like1 element by proteins like fra 2 could prevent the binding of CREB-inhibitory factors (CAPs) in the close vicinity through steric hindrance and, consequently, could facilitate CREB-mediated trans-activation through $\mathrm{CRE}_{\mathrm{PG}}$. Invalidation of the CRE-like1 sequence would allow the return of CAPs on the promoter to partially inhibit CREB-mediated trans-activation. CRE-like1 could therefore be considered as a $\mathrm{CRE}_{\mathrm{PG}}$ 'modulator' element.

The peptone treatment did not seem to modify the nature or the quantity of transcription factors bound to $\mathrm{CRE}_{\mathrm{PG}}$ and to CRE-like1, suggesting that post-translational modifications of already bound factors might be implicated in transcriptional activation, especially phosphorylations. CREB is activated in response to increased concentrations of cAMP and/or $\mathrm{Ca}^{2+}$ via phosphorylation of a specific serine residue by protein kinase A (PKA), calcium/calmodulin-dependent protein kinases II and IV (CaMKII/IV), MAPK-activated protein kinases 2/3 or ribosomal S6 kinases (RSK1-3) [35]. The phosphorylated form of CREB is then able to bind CBP and recruit it to the promoter to provide further bridging to the preinitiation complex. In STC-
1 cells, peptones had been shown to induce a rise of intracellular cAMP levels, and to increase CREB phosphorylation through PKA, MAPK and CaMK pathways [25]. Since the functional involvement of PKA, but also of MAPK and CAMK (data not shown) in the peptone-induced $P G$ promoter activation has been confirmed in the present work, the key functional role of CREB phosphorylation is clearly emphasised. Moreover, collaboration between several promoter elements, not restricted to CREB binding sites, may be necessary to achieve transcriptional regulation of target genes by cAMP second messenger [36, 37]. We observed that the regulation of PG promoter by peptones implicates several promoter elements, differently from CCK promoter in which we identified a single PepRE element [24]. Beside the major role played by both CRE like-1 and $\mathrm{CRE}_{\mathrm{PG}}$, other elements located in $P G$ promoter sequences Pep reg1 ($689 \mathrm{bp} /-350 \mathrm{bp})$ and Pep reg3 (-292 bp/-136 bp) might also play a role in the peptone-induced control of gene transcription. In the well characterised Pep reg3 region, the G2 element [9] could be one such element since recent work has shown that PKA stimulation increased the transcription of a G2-driven reporter gene in enteroendocrine cells [37]. The G1 and G3 [9] elements could also represent candidates since they bind Pax6 whose trans-activation domain can be phosphorylated by MAPKs [38]. Finally, the role of a CCAAT/enhancer binding proteins binding site located in the sequence Pep reg1 should be considered, since compelling evidence supports the role of these factors as cAMP-responsive nuclear regulators [39].

To date, peptones represent the most potent reported stimulant of $P G$ gene transcription in STC-1 enteroendocrine cells, with an average eight- to tenfold induction of the promoter activity. In similar experiments, GRP stimulated $P G$ transcription with a maximal fivefold induction [14]. Moreover, the effect of peptones on the $P G$ promoter is two- to threefold greater than that on the $C C K$ promoter [24], consistent with previous observations showing that peptone treatment increased $P G$ mRNA more than $C C K$ mRNA in STC-1 cells [40]. The peptone-induced $P G$ gene activation was restricted to intestinal cells and was not observed using pancreatic cell lines [40]. Furthermore, peptones stimulate glucose-dependent insulinotropic peptide (GIP) secretion, but did not modulate the GIP mRNA content both in vivo [41] and in STC-1 cells (M. Cordier-Bussat, unpublished results), even though the GIP promoter contains several functional CREs [42], suggesting once again the involvement of other promoter elements.

Defining the molecular basis of the $P G$ gene transcriptional stimulation in the enteroendocrine cell line STC-1 suggests that protein hydrolysates may be physiological stimulants of GLPs in vivo. The assumption can be tested against the characteristics of $\mathrm{L}$ cells. This endocrine subpopulation is present in the 
distal part of the small bowel, where luminal stimulation by incompletely processed protein hydrolysates is conceivable. Using the rat isolated ileum experimental model, peptones were shown to induce significant release of GLP-1 [7, 8]. Similar observations were made using a rat isolated colon preparation [8]. At this level however, the luminal input of dietary proteins is likely to be negligible except in pathological conditions such as malabsorption or short-bowel syndrome. Instead, the colonic mucosa is exposed to large amount of microorganisms in which proteins account for $55 \%$ of their dry mass [43]. Though the hypothesis has yet to be proven, proteolysis of dead microorganisms in the colonic lumen is likely to provide significant amounts of partially degraded proteins [43, 44, 45]. Recently, adenoviral delivery of the transcription factor Pax6 in the rat colonic epithelium has been shown to enhance $P G$ gene transcription in the intestinal mucosa [46], suggesting that the stimulation of endogenous GLPs synthesis by external stimuli could represent an alternate approach to GLP administration. These data and our present work drawn from procedures mimicking dietary stimulation provide new clues to enhance the synthesis of proglucagon-derived peptides by intestinal $\mathrm{L}$ cells.

In conclusion, our data emphasise a crucial regulatory role of the $\mathrm{CRE}_{\mathrm{PG}}$ promoter element in enteroendocrine cells, where it can mediate transcriptional responses to physiological stimuli not only of neuronal origin (such as GRP), but also of dietary origin (protein hydrolysates), at least in part via the phosphorylation of the transcription factor CREB. In alpha pancreatic cells, a pharmacologicallyinduced rise in intracellular cAMP or calcium levels was reported to increase transcription via $\mathrm{CRE}_{\mathrm{PG}}$ but no physiological stimulant had ever been reported to modulate transcription through this element. Moreover, our work points out the role of a previously unsuspected CRE-like1 element as well as of non characterised promoter sequences that are required to achieve the fine tuning of $P G$ promoter regulation via cAMP- and $\mathrm{Ca}^{2+}$-dependent pathways activated by peptone treatment.

Acknowledgments. The authors wish to thank Dr. Charles Vinson and Dr. G. Stanley McKnight for the gifts of plasmids and Cécile Vercherat for her kind help with DNA sequencing. J.C. Gevrey and M. Malapel are recipients of $\mathrm{PhD}$ grants from the French Ministère de l'Education Nationale, de la Recherche et de la Technologie.

\section{References}

1. Nauck MA (1998) Glucagon-like peptide 1 (GLP-1): a potent gut hormone with a possible therapeutic perspective. Acta Diabetol 35:117-129

2. Drucker DJ (2002) Biological actions and therapeutic potential of the glucagon-like peptides. Gastroenterology 122:531-544
3. Hoyt EC, Lund PK, Winesett DE et al. (1996) Effects of fasting, refeeding, and intraluminal triglyceride on proglucagon expression in jejunum and ileum. Diabetes 45 : 434-439

4. Nian M, Gu J, Irwin DM, Drucker DJ (2002) Human glucagon gene promoter sequences regulating tissue-specific versus nutrient-regulated gene expression. Am J Physiol 282:R173-R183

5. Reimer RA, McBurney MI (1996) Dietary fiber modulates intestinal proglucagon messenger ribonucleic acid and postprandial secretion of glucagon-like peptide-1 and insulin in rats. Endocrinology 137:3948-3956

6. Reimer RA, Thomson AB, Rajotte RV, Basu TK, Ooraikul B, McBurney MI (1997) A physiological level of rhubarb fiber increases proglucagon gene expression and modulates intestinal glucose uptake in rats. J Nutr 127:1923-1928

7. Dumoulin V, Moro F, Barcelo A, Dakka T, Cuber JC (1998) Peptide YY, glucagon-like peptide-1, and neurotensin responses to luminal factors in the isolated vascularly perfused rat ileum. Endocrinology 139:3780-3786

8. Cordier-Bussat M, Bernard C, Levenez F et al. (1998) Peptones stimulate both the secretion of the incretin hormone glucagon-like peptide 1 and the transcription of the proglucagon gene. Diabetes 47:1038-1045

9. Philippe J (1991) Structure and pancreatic expression of the insulin and glucagon genes. Endocr Rev 12:252-271

10. Jin T, Drucker DJ (1996) Activation of proglucagon gene transcription through a novel promoter element by the caudal-related homeodomain protein $\mathrm{cdx}-2 / 3$. Mol Cell Biol 16:19-28

11. Hill ME, Asa SL, Drucker DJ (1999) Essential requirement for Pax6 in control of enteroendocrine proglucagon gene transcription. Mol Endocrinol 13:1474-1486

12. Lee YC, Asa SL, Drucker DJ (1992) Glucagon gene 5'flanking sequences direct expression of simian virus 40 large $\mathrm{T}$ antigen to the intestine, producing carcinoma of the large bowel in transgenic mice. J Biol Chem 267:1070510708

13. Jin T, Drucker DJ (1995) The proglucagon gene upstream enhancer contains positive and negative domains important for tissue-specific proglucagon gene transcription. Mol Endocrinol 9:1306-1320

14. Lü F, Jin T, Drucker DJ (1996) Proglucagon gene expression is induced by gastrin-releasing peptide in a mouse enteroendocrine cell line. Endocrinology 137:3710-3716

15. Gajic D, Drucker DJ (1993) Multiple cis-acting domains mediate basal and adenosine $3^{\prime}, 5^{\prime}$-monophosphate-dependent glucagon gene transcription in a mouse neuroendocrine cell line. Endocrinology 132:1055-1062

16. Abello J, Ye F, Bosshard A, Bernard C, Cuber JC, Chayvialle JA (1994) Stimulation of glucagon-like peptide1 secretion by muscarinic agonist in a murine intestinal endocrine cell line. Endocrinology 134:2011-2017

17. Jin T, Drucker DJ (1995) The proglucagon gene upstream enhancer contains positive and negative domains important for tissue-specific proglucagon gene transcription. Mol Endocrinol 9:1306-1320

18. Ahn S, Olive M, Aggarwal S, Krylov D, Ginty DD, Vinson C (1998) A dominant-negative inhibitor of CREB reveals that it is a general mediator of stimulus-dependent transcription of c-fos. Mol Cell Biol 18:967-977

19. Correll LA, Woodford TA, Corbin JD, Mellon PL, McKnight GS (1989) Functional characterization of cAMP-binding mutations in type I protein kinase. J Biol Chem 264:16672-16678

20. Philippe J, Drucker DJ, Knepel W, Jepeal L, Misulovin Z, Habener JF (1988) Alpha-cell-specific expression of the 
glucagon gene is conferred to the glucagon promoter element by the interactions of DNA-binding proteins. Mol Cell Biol 8:4877-4888

21. Rindi G, Grant SG, Yiangou Y et al. (1990) Development of neuroendocrine tumors in the gastrointestinal tract of transgenic mice. Heterogeneity of hormone expression. Am J Pathol 136:1349-1363

22. Dignam JD, Lebovitz RM, Roeder RG (1983) Accurate transcription initiation by RNA polymerase II in a soluble extract from isolated mammalian nuclei. Nucleic Acids Res 11:1475-1489

23. Montminy MR, Sevarino KA, Wagner JA, Mandel G, Goodman RH (1986) Identification of a cyclic-AMP-responsive element within the rat somatostatin gene. Proc Natl Acad Sci USA 83:6682-6686

24. Bernard C, Sutter A, Vinson C, Ratineau C, Chayvialle JA, Cordier-Bussat M (2001) Peptones stimulate intestinal cholecystokinin gene transcription via cyclic adenosine monophosphate response element-binding factors. Endocrinology 142:721-729

25. Gevrey JC, Cordier-Bussat M, Nemoz-Gaillard E, Chayvialle JA, Abello J (2002) Corequirement of cyclic AMP- and calcium-dependent protein kinases for transcriptional activation of cholecystokinin gene by protein hydrolysates. J Biol Chem 277:22407-22413

26. Knepel W, Chafitz J, Habener JF (1990) Transcriptional activation of the rat glucagon gene by the cyclic AMPresponsive element in pancreatic islet cells. Mol Cell Biol 10:6799-6804

27. Drucker DJ, Campos R, Reynolds R, Stobie K, Brubaker PL (1991) The rat glucagon gene is regulated by a protein kinase A-dependent pathway in pancreatic islet cells. Endocrinology 128:394-340

28. Schwaninger M, Lux G, Blume R, Oetjen E, Hidaka H, Knepel W (1993) Membrane depolarization and calcium influx induce glucagon gene transcription in pancreatic islet cells through the cyclic AMP-responsive element. J Biol Chem 268:5168-5177

29. Drucker DJ, Brubaker PL (1989) Proglucagon gene expression is regulated by a cyclic AMP-dependent pathway in rat intestine. Proc Natl Acad Sci USA 86:3953-3957

30. Drucker DJ, Jin T, Asa SL, Young TA, Brubaker PL (1994) Activation of proglucagon gene transcription by protein kinase-A in a novel mouse enteroendocrine cell line. Mol Endocrinol 8:1646-1655

31. Cvekl A, Sax CM, Bresnick EH, Piatigorsky J (1994) A complex array of positive and negative elements regulates the chicken alpha A-crystallin gene: involvement of Pax-6, USF, CREB and/or CREM, and AP-1 proteins. Mol Cell Biol 14:7363-7376

32. Brockmann D, Putzer BM, Lipinski KS, Schmucker U, Esche H (1999) A multiprotein complex consisting of the cellular coactivator $\mathrm{p} 300, \mathrm{AP}-1 / \mathrm{ATF}$, as well as NF-kappaB is responsible for the activation of the mouse major histocompatibility class I $(\mathrm{H}-2 \mathrm{~K}(\mathrm{~b}))$ enhancer A. Gene Expr 8:1-18

33. Bakiri L, Matsuo K, Wisniewska M, Wagner EF, Yaniv M (2002) Promoter specificity and biological activity of tethered AP-1 dimers. Mol Cell Biol 22:4952-4964

34. Miller CP, Lin JC, Habener JF (1993) Transcription of the rat glucagon gene by the cyclic AMP response elementbinding protein CREB is modulated by adjacent CREB-associated proteins. Mol Cell Biol 13:7080-7090

35. Shaywitz AJ, Greenberg ME (1999) CREB: a stimulus-induced transcription factor activated by a diverse array of extracellular signals. Annu Rev Biochem 68:821-861

36. Waltner-Law M, Duong DT, Daniels MC et al. (2003) Elements of the glucocorticoid and retinoic acid response units are involved in cAMP-mediated expression of the PEPCK gene. J Biol Chem 278:10427-10435

37. Ni Z, Anini Y, Fang X, Mills G, Brubaker PL, Jin T (2003) Transcriptional activation of the proglucagon gene by lithium and Beta-catenin in intestinal endocrine L cells. J Biol Chem 278:1380-1387

38. Mikkola I, Bruun JA, Bjorkoy G, Holm T, Johansen T (1999) Phosphorylation of the transactivation domain of Pax6 by extracellular signal-regulated kinase and p38 mitogen-activated protein kinase. J Biol Chem 274:1511515126

39. Wilson HL, Roesler WJ (2002) CCAAT/enhancer binding proteins: do they possess intrinsic cAMP-inducible activity? Mol Cell Endocrinol 188:15-20

40. Cordier-Bussat M, Bernard C, Haouche S et al. (1997) Peptones stimulate cholecystokinin secretion and gene transcription in the intestinal cell line STC-1. Endocrinology 138:1137-1144

41. Wolfe MM, Zhao KB, Glazier KD, Jarboe LA, Tseng CC (2000) Regulation of glucose-dependent-insulinotropic polypeptide release by protein in the rat. Am J Physiol 279:G561-G566

42. Someya Y, Inagaki N, Maekawa T, Seino Y, Ishii S (1993) Two 3',5'-cyclic-adenosine monophosphate response elements in the promoter region of the human gastric inhibitory polypeptide gene. FEBS Lett 317:67-73

43. Cummings JH, MacFarlane GT (1997) Colonic microflora: nutrition and health. Nutrition 13:476-478

44. MacFarlane GT, Cummings JH, Allison C (1984) Protein degradation by human intestinal bacteria. J Gen Microbiol 132:1647-1656

45. Bustos D, Tiscornia O, Caldarini MI et al. (1994) Colonic proteolysis following pancreatic duct ligation in the rat. Int J Pancreatol 16:45-49

46. Trinh DK, Zhang K, Hossain M, Brubaker PL, Drucker DJ (2003) Pax-6 activates endogenous proglucagon gene expression in the rodent gastrointestinal epithelium. Diabetes 52:425-433 